\title{
Effect of Humidified Noninvasive Ventilation on the Development of Facial Skin Breakdown
}

\author{
Jaber Saud Alqahtani MSc, Peter Worsley PhD, and David Voegeli PhD
}

\begin{abstract}
BACKGROUND: The use of noninvasive ventilation masks is known to cause damage to facial skin tissue, which affects both the efficacy of the intervention and the patient's quality of life. The use of humidification with noninvasive ventilation is a common practice, but its relative role in the development of facial pressure ulcers has not been fully studied. METHODS: A crossover cohort design was used in this study, with 15 healthy volunteers. Each volunteer randomly received both $10 \mathrm{~cm} \mathrm{H}_{2} \mathrm{O}$ of CPAP with and without humidification through an oronasal mask. Skin integrity was evaluated by measuring transepidermal water loss, skin hydration, and skin $\mathrm{pH}$ at the bridge of the nose. Device-skin interface conditions (pressure and microclimate) were recorded at the bridge of the nose and both cheeks. The pro-inflammatory cytokine interleukin-1 $\alpha$ was collected from the nose bridge before and after CPAP application by using a skin analysis tape. Nasal symptoms were collected by using a validated 6-point score. RESULTS: Humidified CPAP significantly increased transepidermal water loss $(P<.001)$ and skin humidity $(P=.02)$ compared with non-humidified CPAP. There were no significant differences in skin hydration, skin $\mathrm{pH}$, skin temperature, and cytokine expression between both conditions. However, there was a trend of increased median ratios of interleukin-1 $\alpha$ concentrations in the humidified CPAP. There was a significant increase in the interface pressure at the bridge of the nose after CPAP application $(P=.02)$, with higher interface pressure values at the nose bridge compared with both left $(P=.002)$ and right $(P=.003)$ cheeks. The participants reported elevated nasal discomfort during non-humidified CPAP. CONCLUSIONS: These findings indicated that noninvasive ventilation with humidification had a potential disrupting effect on the barrier function of facial skin, associated with changes in skin microclimate and function. Further research is required to establish the cause of mask-related skin damage and to evaluate the effects of mask design, application techniques, and air flow and humidity settings. Key words: noninvasive ventilation; pressure ulcer; skin damage; skin hydration; skin integrity; interface pressure; skin microclimate; face mask; humidification. [Respir Care 2018;63(9):1102-1110. (c) 2018 Daedalus Enterprises]
\end{abstract}

\section{Introduction}

The use of noninvasive ventilation (NIV) has increased significantly over the past 2 decades and is now the first

Mr Alqahtani is affiliated with Respiratory Care Department, Prince Sultan Military College of Health Sciences, Dhahran, Saudi Arabia. Drs Worsley and Voegeli are affiliated with Southampton General Hospital, Clinical Academic Facility, Faculty of Health Sciences, University of Southampton, Southampton, United Kingdom.

This study was funded by the Saudi Arabia Ministry of Education. The work was supported by the Engineering and Physical Sciences Research Council (EPSRC)-National Institutes for Health Research (NIHR) line of applied therapy for conditions that cause acute respiratory failure. ${ }^{1}$ NIV refers to the delivery of positive pressure support to patients without using invasive endotracheal intubation, commonly via a mask. ${ }^{2}$ NIV de-

\footnotetext{
"Medical Device and Vulnerable Skin" Network and NetworkPLUS (EP/M000303/1 and EP/N02723X/1).

The authors have disclosed no conflicts of interest.

Correspondence: Jaber Saud Alqahtani MSc, Department of Respiratory Care, Prince Sultan Military College of Health Sciences, Dhahran, P.O. Box 33048, Dammam 31448 Saudi Arabia. E-mail: Jaber@psmchs.edu.sa.
}

DOI: $10.4187 /$ respcare. 06087 
vices are currently applied in the ICU, emergency department, step-down areas, respiratory wards, and community settings. ${ }^{2-5}$ The primary use for NIV is to support patients with acute respiratory failure, to avoid the increased mortality and morbidity related to invasive ventilation. ${ }^{6-8}$

Despite the cardiorespiratory benefits of NIV use, there is a common adverse effect that may result from using these devices, namely, the development of facial pressure ulcers.9-11 Recent studies reported rates of facial skin breakdown between 2 and $50 \%$ in the first hours of NIV use and increasing to $100 \%$ after 48 h. ${ }^{12}$ A pressure ulcer is defined as a localized injury to the skin and/or underlying tissue, usually over a bony prominence, as a result of pressure or pressure in combination with shear. ${ }^{13}$ Pressure ulcers lead to increased complications and reduced quality of life for the patient. ${ }^{14,15}$ There is recent evidence that medical devices caused $\sim 34 \%$ of all hospital-acquired pressures ulcers. ${ }^{16}$ Factors implicated in their development include generic designs and the use of stiff polymers, which impinge vulnerable skin tissues. ${ }^{13}$

Studies investigated the relationship between NIV interfaces and the development of pressure ulcers. ${ }^{17-19}$ The bridge of the nose and maxillary area of the face have been reported as the areas most at risk from pressure damage. These studies ${ }^{17-19}$ primarily focused on identifying the location and degree of pressure associated with such interfaces. A recent study ${ }^{20}$ showed that the respiratory mask design and strap tension have a significant effect on the biomechanical interaction on the skin. In addition, this study revealed that were was an associated inflammatory reaction at the skin surface during mask application, which provided a potential indicator for early skin damage; however, this study did not consider the effects of positive pressure or humidity when assessing mask application. ${ }^{20}$ During NIV, adequate gas conditioning is essential because of the deleterious effects of inhalation of dry air, which may then negatively influence adherence to and success of the ventilatory treatment. The correct application of an appropriate humidification system may help prevent NIV-induced airway dryness and promote the transport of secretions from the lungs. ${ }^{21}$ However, to date, to our knowledge, no single study exists that examined the relationship between ventilation settings and humidification applied with NIV and the development of facial pressure ulcers. Indeed, increased humidity and raised temperature affect both the structural and physiologic capability of skin to withstand pressure. ${ }^{22,23}$ There is a need for further investigation to explore how pressure and microclimate changes affect skin health during medical device application. This study aimed to investigate the effects of humidified and non-humidified NIV on skin barrier function.

\section{QUICK LOOK}

\section{Current knowledge}

Noninvasive ventilation (NIV) has become a common intervention in the management of acute respiratory failure. Despite its effectiveness, facial pressure ulcers are a serious adverse effect of using these interfaces and pose a considerable clinical challenge.

\section{What this paper contributes to our knowledge}

Humidification use with NIV potentially increased the risk of facial skin pressure ulcers as evidenced by the disrupting effect on barrier function of the underlying skin and associated trends in inflammatory response. Prophylactic strategies to maintain adequate skin microclimate with appropriate NIV settings are needed to safeguard skin integrity because wetter skin is at greater risk of maceration and friction injury.

\section{Methods}

\section{Subjects}

Fifteen healthy participants were recruited from the local university population through poster advertisement. Exclusion criteria were the following: patients with any respiratory problems, preexisting health disorders that could alter skin vasculature, preexisting skin conditions, and current or intermittent use of vasoactive drugs. Ethical approval was obtained from the local research ethics committee (FoHS-ETHICS-2016-18349), and all the subjects provided informed consent before their involvement.

\section{Design}

A crossover cohort design was used in this study. The participants served as their own controls and received both CPAP with and without humidification. Positive-pressure ventilation was delivered by a standard CPAP system (Trend II Fixed CPAP, Hoffrichter, Schwerin, Germany) at $10 \mathrm{~cm} \mathrm{H}_{2} \mathrm{O}$ pressure. Humidification was delivered by using a heated humidifier, with heat output ranges from levels 1 to 5: level 1 represents the lowest heat output and level 5 represents the maximum heat output. The humidification level was set at 5 , and the intensity of the humidification provided through the humidifier was $\geq 13 \mathrm{mg} / \mathrm{L}$. Level 5 was used because CPAP of $10 \mathrm{~cm} \mathrm{H}_{2} \mathrm{O}$ was delivered, which is sufficient to have adequate humidification at this pressure level according to the user's manual for the humidifier. An oronasal mask (Mirage Quattro, ResMed, San Diego, California) was used with each sub- 
ject and fitted with according to manufacturer and clinical guidelines. ${ }^{24}$ The commercially available oronasal mask was chosen because this mask is routinely used to treat acute respiratory failure in local clinical sites..$^{25}$

\section{Measurement Equipment}

To measure biophysical skin properties before and after NIV application, an array of measurements was taken. The TM300 instrument (Courage + Khazaka, Cologne, Germany) was used to assess skin barrier function by measuring transepidermal water loss via an open chamber probe applied to the skin surface. ${ }^{26}$ Skin hydration was assessed by using a Corneometer (model CM825, Courage + Khazaka). In addition, a pH electrode (model PH905, Courage + Khazaka) was used to measure skin surface $\mathrm{pH}$. An Oxford pressure monitor (Talley Group, Romsey, United Kingdom) was used to record interface pressures at the device-skin interface, which involves applying 18-mmdiameter sensor pads between the mask and the skin and which has been reported to have a mean error of $12 \pm 1 \%$ and repeatability of $\pm 0.53 \mathrm{~mm} \mathrm{Hg} .{ }^{27}$ Skin microclimate was recorded by using a combined sensor (SHT75, Sensirion, Stäfa, Switzerland). This sensor is able to measure relative humidity $(\mathrm{RH})$ and temperature, with an accuracy of $\pm 1.8 \%$ for $\mathrm{RH}$ and $\pm 0.4^{\circ} \mathrm{C}$ of its measured value for temperature. ${ }^{28}$

Subject comfort was assessed by using a visual analog scale, which ranged from 0 to 10 , with 0 representing no discomfort and 10 extreme discomfort. ${ }^{29}$ Nasal symptoms (rhinorrhea, post-nasal drip, nasal congestion, sneezing, reduced sense of smell, and itchy nose) were evaluated before and after CPAP by using a 6-point nasal score. This score has been validated and is used to determine the absence or presence of nasal symptoms. ${ }^{30}$ Pro-inflammatory cytokine (IL-1 $\alpha$ ) released by the skin was collected by using Sebutape (CuDerm, Dallas, Texas). A standardized sampling method was used, as previously described by Perkins et al. ${ }^{31}$

\section{Study Protocol}

The research was conducted within a clinical research facility, which allowed controlled ambient temperature and humidity to be maintained at $21 \pm 2^{\circ} \mathrm{C}$ and $40 \pm 5 \%$, respectively. There was an acclimatization period of $20 \mathrm{~min}$ for each participant. The participants attended 2 sessions on non-consecutive days, which allowed a gap of at least $48 \mathrm{~h}$ between experimental visits. Selection of NIV with and without humidification was randomly allocated manually by using shuffling cards. The subjects were asked to report any nasal symptoms before the test by using the 6-point nasal score as a baseline. Mask fitting for the participants was applied before starting CPAP to deter- mine the optimal fit for each subject. An optimum fit was defined by tensioning to a point at which 2 fingers could be slid between the straps and the skin. ${ }^{32}$ Once the appropriate mask fit was determined, all 4 strap tensions were marked to ensure that the same fit was maintained for each test condition.

Before placement of the mask, a baseline measurement for skin barrier function (transepidermal water loss, skin $\mathrm{pH}$, and Corneometer) was collected from the bridge of the nose of each subject after a period of 1 min, with each measure taken over a 1-min period. The Sebutape was applied, with gentle pressure, for $2 \mathrm{~min}$ on the bridge of the nose of the subjects to collect baseline cytokine. Once the mask was applied, without CPAP, a baseline measurement for 3 pressure values at the bridge of the nose and the superomedial part of the left and right cheeks were recorded on the same optimum mask fit for each subject. This was achieved by placing sensor pads at the interface between the skin and the mask at the previous areas for a 2-min collection period. After these pressures were recorded, the pads were removed, and a combined microclimate sensor was placed at the superomedial aspect of the left cheek between the mask and the skin for $1 \mathrm{~min}$. Once baseline variables were recorded, the subjects were exposed to CPAP of $10 \mathrm{~cm} \mathrm{H}_{2} \mathrm{O}$ for $30 \mathrm{~min}$. Throughout the procedure, the participants were monitored by the investigators for any adverse effects. After 15 min of intervention, measurements of interface pressures and the skin microclimate were repeated. The participants were asked to rate their comfort after $25 \mathrm{~min}$ elapsed. After $30 \mathrm{~min}$, post-intervention values of skin integrity markers, cytokines, and nasal symptoms were collected.

\section{Data Analysis}

Data were analyzed by using IBM SPSS statistics V22 (IBM, Armonk, New York). Normality was assessed by using a Kolmogorov-Smirnov test. Data were represented as mean $\pm \mathrm{SD}$ if normally distributed or as median and interquartile range if not normally distributed. Absolute values for cytokine concentration before and after the CPAP intervention were obtained from the Sebutape samples and expressed as $\mathrm{pg} / \mathrm{mL}$ of total protein. The cytokine levels were normalized to total protein content. Ratios were calculated from absolute values for each session, from baseline and post-intervention concentrations. To assess the effect of CPAP alone on interface pressures, a Wilcoxon signed-rank test was used to evaluate the differences between pre- and post-CPAP values for non-humidified CPAP only to eliminate the additive effect of humidification on those pressures. A Wilcoxon signed-rank test was performed on non-parametric skin integrity markers, skin microclimate, comfort score data, and differences in cytokine concentrations between pre- and post-CPAP use in humid- 
Table 1. Changes of Skin Integrity Markers and Skin Microclimate Before and After CPAP in Humidified and Non-Humidified CPAP

\begin{tabular}{|c|c|c|c|c|c|c|}
\hline \multirow[b]{2}{*}{ Variable Measured } & \multicolumn{3}{|c|}{ Humidified CPAP } & \multicolumn{3}{|c|}{ Non-Humidified CPAP } \\
\hline & $\begin{array}{c}\text { Baseline } \\
\text { Measurement, } \\
\text { median (IQR) }\end{array}$ & $\begin{array}{l}\text { Post } \\
\text { Measurement, } \\
\text { median (IQR) }\end{array}$ & $P$ & $\begin{array}{c}\text { Baseline } \\
\text { Measurement, } \\
\text { median (IQR) }\end{array}$ & $\begin{array}{l}\text { Post } \\
\text { Measurement, } \\
\text { median (IQR) }\end{array}$ & $P$ \\
\hline TEWL, $\mathrm{g} / \mathrm{h} / \mathrm{m}^{2}$ & $11.2(7.0-15.2)$ & $20.2(17.3-30.7)$ & $<.001$ & $14.9(7.6-24.5)$ & $17.8(9.1-28.7)$ & .86 \\
\hline Skin $\mathrm{pH}$ & $5.3(5.2-5.6)$ & $5.5(5.5-5.6)$ & .20 & $5.2(4.9-55.0)$ & $5.4(5.3-5.5)$ & .17 \\
\hline Corneometer, a.u. & $42.3(30.7-53.1)$ & $62.5(55.5-64.1)$ & $<.001$ & $47.0(36.7-53.4)$ & $58.8(48.8-64.7)$ & .004 \\
\hline Skin temperature, ${ }^{\circ} \mathrm{C}$ & $34.0(32.7-34.4)$ & $34.0(32.8-34.7)$ & .65 & $33.5(31.7-34.4)$ & $33.8(32.8-34.1)$ & .12 \\
\hline Skin RH, \% & $43.0(36.9-43.1)$ & $68.8(63.7-72.0)$ & $<.001$ & $38.3(35.5-44.0)$ & $62.1(54.4-66.1)$ & $<.001$ \\
\hline \multicolumn{7}{|c|}{$\begin{array}{l}\mathrm{IQR}=\text { interquartile range } \\
\mathrm{TEWL}=\text { transepidermal water loss } \\
\mathrm{RH}=\text { relative humidity }\end{array}$} \\
\hline
\end{tabular}

ified and non-humidified CPAP. A chi-square test was applied to compare nasal symptoms before and after CPAP in both groups. Statistical significance was defined as $P<.05$.

\section{Results}

\section{Participants}

Fifteen healthy participants (10 men and 5 women) were recruited. Their demographics (mean $\pm \mathrm{SD}$ ) were as follows: age, $26 \pm 2 \mathrm{y}$; weight, $66.9 \pm 10.6 \mathrm{~kg}$; and height, $1.7 \pm 7.4 \mathrm{~m}$, with corresponding body mass index values of $22.8 \pm 2.3 \mathrm{~kg} / \mathrm{m}^{2}$.

\section{Transepidermal Water Loss}

There were significantly higher values of transepidermal water loss after humidified CPAP compared with the baseline $(P<.001)$, which increased from 11.2 to $20.2 \mathrm{~g} / \mathrm{h} / \mathrm{m}^{2}$ after the humidification. No significant difference was seen in the non-humidified CPAP $(P=.86)$ (Table 1). The significant increase in transepidermal water loss in the humidified CPAP compared with non-humidified CPAP $(P<.001)$ is shown in Figure 1 .

\section{Skin pH and Skin Hydration}

No significant differences in skin $\mathrm{pH}$ were seen between these conditions. However, there was a significant rise in skin hydration in both conditions. With humidified CPAP and non-humidified CPAP, skin hydration increased from a baseline of 42.3 to 62.5 a.u. $(P<.001)$ and from 47.0 to 58.8 a.u. $(P=.004)$, respectively. Analysis of the results, as shown in Table 1 , indicated no statistically significant difference between the 2 conditions $(P=.065)$. However, we observed trends toward increased hydration with humidified CPAP.

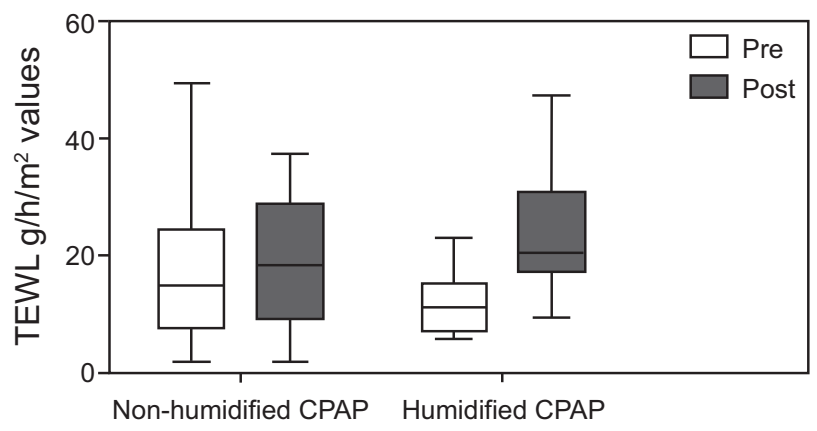

Fig. 1. Transepidermal water loss (TEWL) measurements. Lines represent median, boxes represent interquartile ranges, and whiskers denote range. There was a significant increase in median TEWL with the humidified CPAP compared with the non-humidified CPAP $(P<.001)$.

\section{Skin Microclimate}

There were statistically significant differences in skin humidity between the 2 conditions $(P=.02)$. RH increased from $43 \%$ at baseline to $68.8 \%$ with humidified CPAP and from $38.3 \%$ to $62.1 \%$ for non-humidified CPAP. In Figure 2, there is shown a clear rise in the median difference of skin humidity between humidified and nonhumidified CPAP. No significant differences were observed in the skin temperature between the 2 conditions (Table 1 ).

\section{Interface Pressures}

Analysis of the interface pressures at baseline revealed significantly higher median values at the bridge of the nose compared with the left cheek [110 (92-130) $\mathrm{mm} \mathrm{Hg}$ vs $71(63-87) \mathrm{mm} \mathrm{Hg}, P=.02]$ and the right cheek [110 (92-130) $\mathrm{mm} \mathrm{Hg}$ vs 79 (59-90) $\mathrm{mm} \mathrm{Hg}, P=.003]$. Interface pressure differences between left and right cheek locations were not statistically significant $(P=.33)$. There was a significant increase in nasal pressures with the ap- 
plication of positive pressure from a baseline of 110 (92130) $\mathrm{mm} \mathrm{Hg}$ to $115(103-130) \mathrm{mm} \mathrm{Hg}(P=.02)$. The changes in the left and right cheek pressures after CPAP application were not significant (Table 2). The changes in the interface pressures at the nose bridge and both cheeks in non-humidified CPAP at the baseline and after CPAP as demonstrated in Figure 3.

\section{Cytokines}

There was no statistically significant difference in median ratios of the IL- $1 \alpha$ concentrations between baseline and post-CPAP values in the humidified CPAP compared with non-humidified CPAP, 1.52 and 1.05 , respectively (Fig. 4); however, there was a trend of increased ratios of IL- $1 \alpha$ concentrations in the humidified CPAP.

\section{Nasal Symptoms and Subject Comfort}

Changes in the nasal symptoms before and after CPAP in the 2 conditions with the subjects' comfort scores are presented in Tables 3-5. There were no nasal symptoms before CPAP in both groups. A number of participants $(66.7 \%)$ had some discomfort during non-humidified CPAP

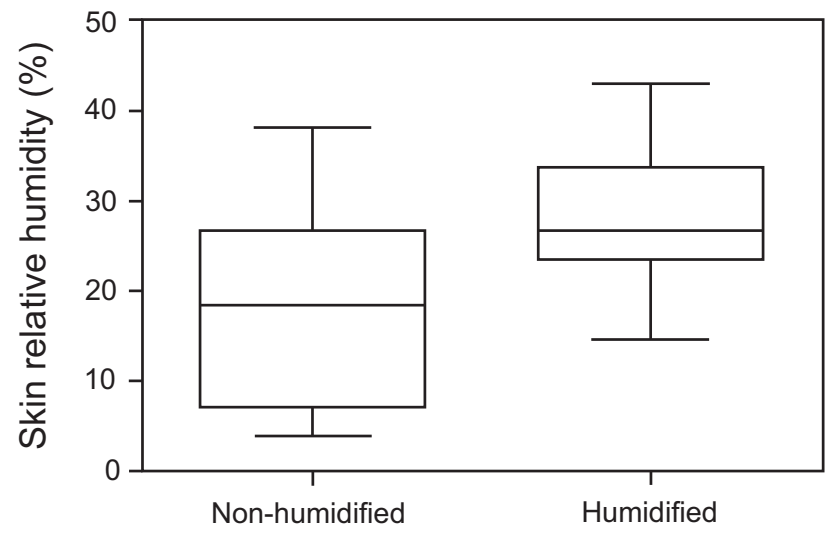

Fig. 2. Changes in skin relative humidity between humidified and non-humidified CPAP. Lines represent median, boxes represent interquartile ranges, and whiskers denote range. ${ }^{*} A$ significant rise in the median difference of skin relative humidity between both conditions $(P=.02)$. application, which resulted in a median score of one. Itchy nose was the most common nasal symptom in both conditions. There was no significant difference in the comfort score between the conditions.

\section{Discussion}

The aim of this study was to investigate the effects of humidified CPAP on the skin microclimate, barrier function, and risk of pressure ulcer development by assessing both interface conditions (pressure and microclimate) and skin biophysical and biochemical measures. This study showed that humidified CPAP significantly increased the local humidity at the skin surface, which resulted in a disruption of barrier function measured by transepidermal water loss. In addition, the results revealed that CPAP used in isolation significantly increased interface pressure at the bridge of the nose, with lower corresponding values measured at the cheeks. Regardless of humidity, CPAP resulted in an increased physiologic response in the form of cytokine release, which may be an early indication of skin damage. ${ }^{33}$ To the best of our knowledge, ours was the first study that investigated the in vivo impact of humidified CPAP on the potential for developing facial pressure ulcers.

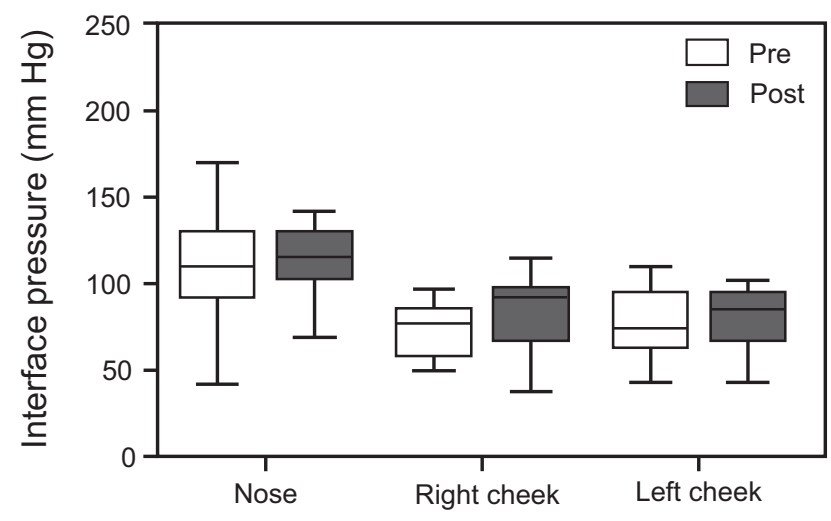

Fig. 3. Changes in the interface pressures before and after nonhumidified CPAP. Lines represent median, boxes represent interquartile ranges, and whiskers denote range.

Table 2. Interface Pressure Differences Before and After CPAP in Humidified and Non-Humidified CPAP

\begin{tabular}{|c|c|c|c|c|c|c|}
\hline \multirow{2}{*}{ Interface Pressure } & \multicolumn{3}{|c|}{ Humidified CPAP } & \multicolumn{3}{|c|}{ Non-Humidified CPAP } \\
\hline & $\begin{array}{l}\text { Pre-CPAP, median } \\
\text { (IQR) mm Hg }\end{array}$ & $\begin{array}{l}\text { Post-CPAP, median } \\
\text { (IQR) mm Hg }\end{array}$ & $P$ & $\begin{array}{l}\text { Pre-CPAP, median } \\
\text { (IQR) mm Hg }\end{array}$ & $\begin{array}{l}\text { Post-CPAP, median } \\
\text { (IQR) mm Hg }\end{array}$ & $P$ \\
\hline Nasal bridge & $110(74-141)$ & $115(79-155)$ & .005 & $110(92-130)$ & $115(103-130)$ & .02 \\
\hline Right cheek & $82(73-93)$ & $91(78-97)$ & .02 & $79(59-90)$ & $92(67-98)$ & .22 \\
\hline Left cheek & $80(74-93)$ & $91(85-97)$ & .01 & $71(63-87)$ & $85(68-94)$ & .34 \\
\hline
\end{tabular}




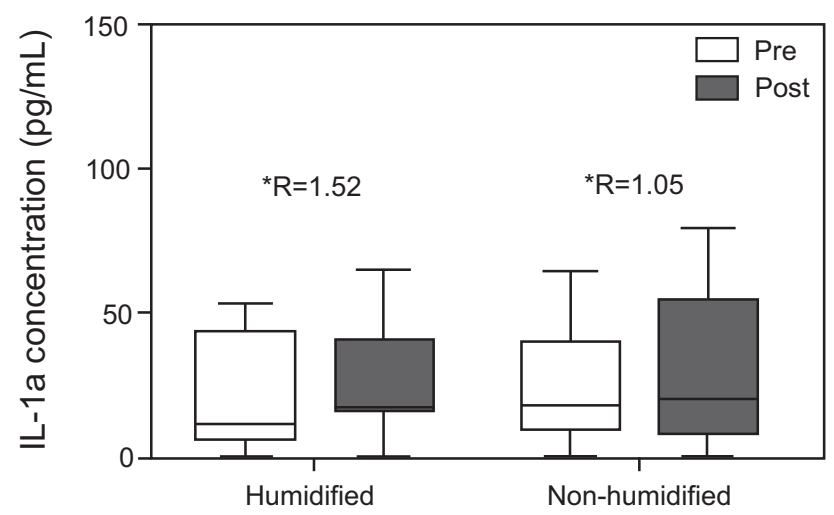

Fig. 4. Concentration of interleukin (IL) $1 \alpha$ at baseline and after CPAP for humidified and non-humidified application. Lines represent median, boxes represent interquartile ranges, and whiskers denote range. ${ }^{*}$ Median ratio between concentrations.

The use of humidification with CPAP disrupted the skin barrier function as evidenced by the rise in transepidermal water loss. ${ }^{34-36}$ Changes in transepidermal water loss are sensitive and happen before clinically observable skin damage. ${ }^{37}$ The comparison between humidified and non-humidified CPAP in our study showed that humidification exposure induced skin alterations in the form of increased water loss, reflected by a significant increase in transepidermal water loss. In contrast, the area that was occluded by the mask without humidification exposure did not show any significant change in transepidermal water loss. These results were consistent with those observed in earlier work by Fartasch et al, ${ }^{37}$ who reported a significant increase in transepidermal water loss after water exposure; however, they measured transepidermal water loss from a different skin site after a exposure period of $2 \mathrm{~h}$, which limits the comparison. Such a rise in skin hydration is associated with the development of conventional pressure ulcers ${ }^{38}$ because excessive moisture softens and weakens the epidermis and makes it susceptible to damage. ${ }^{39,40}$

With regard to the skin microclimate, we found that humidified CPAP resulted in increased skin RH compared with non-humidified CPAP, which was expected. At a RH of $100 \%$, the strength of the stratum corneum was reported to be 25 times weaker than at 50\% RH. ${ }^{41}$ Excessive humidity increases the possibility of skin damage from shear due to the increase in the skin's coefficient of friction. ${ }^{40}$ However, mask leak, either unintentional (around the mask) or intentional (mask or circuit), similarly affects humidity. ${ }^{21}$ There was no statistical difference in skin temperature between humidified and non-humidified CPAP. However, we recorded a relatively high skin temperature, of $34^{\circ} \mathrm{C}$, in both conditions. At $35^{\circ} \mathrm{C}$, the strength of the stratum corneum was reported to be $25 \%$ of that at $30^{\circ} \mathrm{C} .42$ It seems possible that these results were due to the contact with the mask, which resulted in low exposure to air.
Indeed, the temperature of the skin has been shown to alter the tolerance to load. ${ }^{43}$

This study revealed that the bridge of the nose was the site that sustained the highest interface pressures compared with the left and right cheeks during CPAP application. These results were consistent with data obtained by Worsley et al. ${ }^{20}$ They found a significant association between strap tension and nasal interface pressures. The nasal pressure in our study $(115 \mathrm{~mm} \mathrm{Hg})$ was lower compared with their study $(158 \mathrm{~mm} \mathrm{Hg}){ }^{20}$ These differences may have been due to the application of positive pressure and the magnitude of tension exerted by the straps on the bridge of the nose of the subjects. Our study reported higher interface pressures compared with Munckton et al ${ }^{18}$ (bridge of the nose, $63.8 \pm 21.0 \mathrm{~mm} \mathrm{Hg}$; left cheek, $14.4 \pm 7 \mathrm{~mm} \mathrm{Hg}$; right cheek, $15.6 \pm 6.8 \mathrm{~mm} \mathrm{Hg}$ ). Furthermore, Munckton et al ${ }^{18}$ showed that an increase in $\mathrm{CPAP}$ reduced pressure on the bridge of the nose, with no differences in the left and right cheeks. This differs from our findings in which CPAP alone increased nasal interface (the pressure that created on the bridge of the nose) pressures. Although this was statistically significant, the clinical relevance of a $5 \mathrm{~mm} \mathrm{Hg}$ increase was limited. The observed difference in the interface pressures before and after CPAP compared with previous published research could be attributed to diversity in experimental conditions, such as the type of mask, pressure measurement device, and subject's ethnicity. In the present study, there were no significant differences in interface pressures between humidified and non-humidified CPAP, which demonstrated no effect of humidification on interface pressures.

The current study was the first to explore the impact of a period of $30 \mathrm{~min}$ of humidified CPAP on the inflammatory skin response specifically at the bridge of the nose. The cytokine concentrations were not statistically significant between humidified and non-humidified CPAP. However, there were increased ratios of IL- $1 \alpha$ concentrations in the humidified CPAP, which could be a potential marker for early detection of pressure ulcers. ${ }^{44}$ These results supported recent research into this area that found a general increase in the cytokine ratio at the highest strap tension. ${ }^{20}$ However, the IL- $1 \alpha$ ratio in our study (1.52) was higher than the ratio that was reported in their study (1.34). ${ }^{20}$ It seemed possible that such an increase in the IL- $1 \alpha$ ratio was due to the sustained load of the mask and the presence of humidification in our study. However, the observed increases in IL- $1 \alpha$ ratios in our study were far below those described by Cornelissen et $\mathrm{al}^{33}$ (a 2.5 -ratio increase) who measured the inflammatory response of the forearm after application of $100 \mathrm{~mm} \mathrm{Hg}$ loading pressure for a period of $2 \mathrm{~h}$. The observed increase in the ratios of IL- $1 \alpha$ concentrations could be attributed to the different skin site, increased loading time, and amount of pressure applied. Therefore, it is possible that, if our loading time were 
Table 3. Changes in the Nasal Symptoms Score Before and After CPAP in the Humidified and Non-Humidified CPAP

\begin{tabular}{lcccc}
\hline \hline \multirow{2}{*}{\begin{tabular}{c} 
Variable Measured \\
\cline { 2 - 3 }
\end{tabular}} & $\begin{array}{c}\text { Baseline } \\
\text { Measurement }\end{array}$ & $\begin{array}{c}\text { Post } \\
\text { Measurement }\end{array}$ & & $\begin{array}{c}\text { Non-Humidified CPAP } \\
\text { Measurement }\end{array}$ \\
\hline 6 Nasal score, median (IQR) & $0(0)$ & $0(0-1)$ & $0(0)$ & $\begin{array}{c}\text { Post } \\
\text { Measurement }\end{array}$ \\
\hline $\mathrm{IQR}=$ interquartile range & & & $1(0-1)$ \\
\hline
\end{tabular}

Table 4. Prevalence of the Nasal Symptoms Before and After CPAP in the Humidified and Non-Humidified CPAP

\begin{tabular}{lccc}
\hline \hline Nasal Symptoms & $\begin{array}{c}\text { Baseline } \\
\text { Values, } \\
\text { no. (\%) }\end{array}$ & $\begin{array}{c}\text { Humidified } \\
\text { CPAP, } \\
\text { no. (\%) }\end{array}$ & $\begin{array}{c}\text { Non-Humidified } \\
\text { CPAP, no. (\%) }\end{array}$ \\
\hline Rhinorrhea & 0 & $0(0)$ & $0(0)$ \\
Post-nasal drip & 0 & $0(0)$ & $0(0)$ \\
Sneezing & 0 & $1(6.6)$ & $2(6.6)$ \\
Nasal congestion & 0 & $1(6.6)$ & $3(20)$ \\
Anosmia & 0 & $0(0)$ & $0(0)$ \\
Itchy nose & 0 & $2(13.3)$ & $5(33.33)$ \\
\hline
\end{tabular}

Table 5. The Subject's Comfort Score Pre and Post CPAP in the Humidified and Non-Humidified CPAP

\begin{tabular}{lcc}
\hline \hline & $\begin{array}{c}\text { Humidified } \\
\text { CPAP }\end{array}$ & $\begin{array}{c}\text { Non-Humidified } \\
\text { CPAP }\end{array}$ \\
\hline $\begin{array}{l}\text { Discomfort level, median (IQR) } \\
\text { Score, no. (\%) subjects }\end{array}$ & $2(1-2)$ & $2(1-3)$ \\
0 & $3(20)$ & $3(20)$ \\
1 & $4(27)$ & $3(20)$ \\
2 & $7(47)$ & $5(33)$ \\
3 & $1(6.7)$ & $4(27)$ \\
\hline IQR = interquartile range & & \\
\hline
\end{tabular}

$>30 \mathrm{~min}$ in the presence of humidification, a significantly increased IL- $1 \alpha$ ratio may have occurred because humidification makes the skin more vulnerable to damage. ${ }^{40}$

In this study, non-humidified CPAP was found to significantly increase the reporting of nasal symptoms, with more than half of the subjects having at least one symptom after a 30-min exposure period. These results supported previous research that reports a high prevalence of nasal symptoms after non-humidified CPAP. ${ }^{45}$ In contrast, humidified CPAP was associated with less prevalence of nasal symptoms, which suggests that dryness of CPAP pressure increases the acute nasal symptoms after a period of $30 \mathrm{~min}$. The discomfort score was partially increased with the non-humidified CPAP, and this finding was likely to be related to the high prevalence of nasal symptoms that was reported under the same condition.

This study had some limitations. Our research included a small convenience sample of young, healthy volunteers, therefore, our findings could not be generalized to all pop- ulations. The recruited subjects were from different ethnic backgrounds (Europeans, Africans, and Asians) which caused some variability in our data, but this may be considered an advantage because different ethnic backgrounds were represented. This study used only CPAP without pressure support, which limited insights into how these settings affected the outcome measured. The period of CPAP application was relatively short when compared with the NIV clinical application. ${ }^{10}$ Also, we only used an oronasal mask without any protective dressing on the nasal bridge. Different masks and dressing could decrease the effect of pressure on the bridge of the nose. Hence, our findings could not be extrapolated to all other masks or when a protective dressing was applied.

Our findings had important clinical implications. Particularly, by establishing a relationship between NIV with humidification and the risk of developing facial pressure ulcers. These findings had important implications for developing strategies to maintain normal skin hydration, microclimate, and appropriate NIV settings, which may reduce the risk of maceration and friction damage and, therefore, improve patient outcome. Furthermore, clinicians should maintain a vigilant eye on those patients who use NIV with humidification, especially those who may not be able to reposition the interface as facial skin becomes more vulnerable to damage with its use over time. Also, prophylactic dressings could protect skin integrity and thereby should be considered. ${ }^{46}$

\section{Conclusions}

These findings indicated that NIV with humidification had a potential disrupting effect on the barrier function of facial skin and was associated with changes in skin microclimate and function. The results revealed that CPAP alone elevated interface pressure at the bony prominence areas, as evidenced by the increased the interface pressure at the bridge of the nose. Prophylactic schemes to keep the skin dry and redistribute pressures between the mask and the skin are needed to safeguard skin integrity. Further research is warranted to clinically explore the nature of our findings and to establish the cause of mask-related skin damage and to evaluate the effects of mask design, application techniques, and air flow and/or humidity settings. 


\section{NIV With and Without Humidity and SKIN BREAKDOWN}

\section{REFERENCES}

1. Cabrini L, Esquinas A, Pasin L, Nardelli P, Frati E, Pintaudi M, et al. An international survey on noninvasive ventilation use for acute respiratory failure in general non-monitored wards. Resp Care 2015; 60(4):586-592.

2. Nava S, Hill N. Non-invasive ventilation in acute respiratory failure. Lancet 2009;374(9685):250-259.

3. Plaisance P, Pirracchio R, Berton C, Vicaut E, Payen D. A randomized study of out-of-hospital continuous positive airway pressure for acute cardiogenic pulmonary oedema: physiological and clinical effects. Eur Heart J 2007;28(23):2895-2901.

4. Plant PK, Owen JL, Elliott MW. Early use of non-invasive ventilation for acute exacerbations of chronic obstructive pulmonary disease on general respiratory wards: a multicentre randomised controlled trial. Lancet 2000;355(9219):1931-1935.

5. Weitz G, Struck J, Zonak A, Balnus S, Perras B, Dodt C. Prehospital noninvasive pressure for acute cardiogenic pulmonary support ventilation edema. Eur J Emerg Med 2007;14(5):276-279.

6. Hess DR. Noninvasive positive-pressure ventilation and ventilatorassociated pneumonia. Respir Care 2005;50(7):924-929, discussion 929-931.

7. Tomii K, Seo R, Tachikawa R, Harada Y, Murase K, Kaji R, et al. Impact of noninvasive ventilation (NIV) trial for various types of acute respiratory failure in the emergency department; decreased mortality and use of the ICU. Respir Med 2009;103(1):67-73.

8. Vitacca M, Ambrosino N, Clini E, Porta R, Rampulla C, Lanini B, Nava S. Physiological response to pressure support ventilation delivered before and after extubation in patients not capable of totally spontaneous autonomous breathing. Am J Respir Crit Care 2001; 164(4):638-641.

9. Ahmad Z, Venus M, Kisku W, Rayatt SS. A case series of skin necrosis following use of non invasive ventilation pressure masks. Int Wound J 2013;10(1):87-90.

10. Racca F, Appendini L, Berta G, Barberis L, Vittone F, Gregoretti C, et al. Helmet Ventilation for Acute Respiratory Failure and Nasal Skin Breakdown in Neuromuscular Disorders. Anesth Analg 2009; 109(1):164-167.

11. Sleilati FH, Stephan HA, Nasr MW, Riachy MA. An unusual pressure sore of the nasal bridge. Br J Oral Maxillofac Surg 2008;46(5): 411-412.

12. Carron M, Freo U, BaHammam AS, Dellweg D, Guarracino F, Cosentini $\mathrm{R}$, et al. Complications of non-invasive ventilation techniques: a comprehensive qualitative review of randomized trials. Brit J Anaesth 2013;110(6):896-914.

13. National Pressure Ulcer Advisory Panel, European Pressure Ulcer Advisory Panel and Pan Pacific Pressure Injury Alliance. In: Haesler E, editor. Prevention and treatment of pressure ulcers: quick reference guide. Perth, Australia: Cambridge Media; 2014.

14. Coleman S, Nixon J, Keen J, Wilson L, McGinnis E, Dealey C, et al. A new pressure ulcer conceptual framework. J Adv Nurs 2014; 70(10):2222-2234

15. Gorecki C, Brown JM, Nelson EA, Briggs M, Schoonhoven L, Dealey C, et al; European Quality of Life Pressure Ulcer Project group. Impact of pressure ulcers on quality of life in older patients: a systematic review. J Am Geriatr Soc 2009;57(7):1175-1183.

16. Black JM, Cuddigan JE, Walko MA, Didier LA, Lander MJ, Kelpe MR. Medical device related pressure ulcers in hospitalized patients. Int Wound J 2010;7(5):358-365.

17. Dellweg D, Hochrainer D, Klauke M, Kerl J, Eiger G, Kohler D. Determinants of skin contact pressure formation during non-invasive ventilation. J Biomech 2010;43(4):652-657.

18. Munckton K, Ho KM, Dobb GJ, Das-Gupta M, Webb SA. The pressure effects of facemasks during noninvasive ventilation: a volunteer study. Anaesthesia 2007;62(11):1126-1131.
19. Schettino GP, Tucci MR, Sousa R, Valente Barbas CS, Passos Amato $\mathrm{MB}$, Carvalho CR. Mask mechanics and leak dynamics during noninvasive pressure support ventilation: a bench study. Intensive Care Med 2001;27(12):1887-1891.

20. Worsley PR, Prudden G, Gower G, Bader DL. Investigating the effects of strap tension during non-invasive ventilation mask application: a combined biomechanical and biomarker approach. Med Devices (Auckl) 2016;9:409-417.

21. Esquinas Rodriguez AM, Scala R, Soroksky A, BaHammam A, de Klerk A, Valipour A, et al. Clinical review: humidifiers during noninvasive ventilation-key topics and practical implications. Crit Care 2012;16(1):203

22. Gefen A. How do microclimate factors affect the risk for superficial pressure ulcers: A mathematical modeling study. J Tissue Viability 2011;20(3):81-88.

23. Reger SI, Ranganathan VK, Sahgal V. Support surface interface pressure, microenvironment, and the prevalence of pressure ulcers: an analysis of the literature. Ostomy Wound Manage 2007;53(10): $50-58$.

24. Royal College of Physicians, British Thoracic Society, Intensive Care Society. Chronic obstructive pulmonary disease: non-invasive ventilation with bi-phasic positive airways pressure in the management of patients with actute type 2 respiratory failure. Concise Guidance to Good Practice series, No 11. London: RCP, 2008.

25. Crimi C, Noto A, Princi P, Esquinas A, Nava S. A European survey of noninvasive ventilation practices. Eur Respir J 2010;36(2):362369.

26. Fluhr JW, Feingold KR, Elias PM. Transepidermal water loss reflects permeability barrier status: validation in human and rodent in vivo and ex vivo models. Exp Dermatol 2006;15(7):483-492.

27. Allen V, Ryan DW, Lomax N, Murray A. Accuracy of interface pressure measurement systems. J Biomed Eng 1993;15(4):344-348.

28. Limited Company. Sensor Company. Datasheet SHT7x (SHT71 SHaTSSCL, Staefa, ZH, Switzerland, 2011. https://www.sensirion.com/ fileadmin/user_upload/customers/sensirion/Dokumente/0_Datasheets/ Humidity/Sensirion_Humidity_Sensors_SHT7x_Datasheet.pdf. Accessed May 10, 2017.

29. Aitken RC. Measurement of feelings using visual analogue scales. Proc R Soc Med 1969;62(10):989-993.

30. Hurst JR, Wilkinson TM, Perera WR, Donaldson GC, Wedzicha JA. Relationships among bacteria, upper airway, lower airway, and systemic inflammation in COPD. Chest 2005;127(4):1219-1226.

31. Perkins MA, Osterhues MA, Farage MA, Robinson MK. A noninvasive method to assess skin irritation and compromised skin conditions using simple tape adsorption of molecular markers of inflammation. Skin Res Technol 2001;7(4):227-237.

32. Meduri GU, Abou-Shala N, Fox RC, Jones CB, Leeper KV, Wunderink RG. Noninvasive face mask mechanical ventilation in patients with acute hypercapnic respiratory failure. Chest 1991;100(2):445454.

33. Cornelissen LH, Bronneberg D, Bader DL, Baaijens FP, Oomens $\mathrm{CW}$. The transport profile of cytokines in epidermal equivalents subjected to mechanical loading. Ann Biomed Eng 2009;37(5):10071018.

34. Angelova-Fischer I, Wuthe D, Zillikens D, Kahle B. Noninvasive bioengineering assessment of the skin barrier function in patients with chronic venous insufficiency. Br J Dermatol 2010;162(5):1071-1075.

35. Pedersen L, Jemec GB. Mechanical properties and barrier function of healthy human skin. Acta Derm Venereol 2006;86(4):308-311.

36. Marks R, Black D. Methodologies to produce and assess standardized trauma to the skin. Am J Ind Med 1985;8(4-5):491-498.

37. Fartasch M, Taeger D, Broding HC, Schöneweis S, Gellert B, Pohrt U, Brüning T. Evidence of increased skin irritation after wet work: 


\section{NIV With AND Without Humidity and SKIN BREAKDOWN}

impact of water exposure and occlusion. Contact Dermatitis 2012; 67(4):217-228.

38. Visscher MO, White CC, Jones JM, Cahill T, Jones DC, Pan BS. Face Masks for Noninvasive Ventilation: Fit, Excess Skin Hydration, and Pressure Ulcers Respir Care 2015;60(11):1536-1547.

39. Yusuf S, Okuwa M, Shigeta Y, Dai M, Iuchi T, Rahman S, et al. Microclimate and development of pressure ulcers and superficial skin changes. Int Wound J 2015;12(1):40-46.

40. Gerhardt LC, Strässle V, Lenz A, Spencer ND, Derler S. Influence of epidermal hydration on the friction of human skin against textiles. J R Soc Interface 2008;5(28):1317-1328.

41. Brienza DM, Geyer MJ. Using support surfaces to manage tissue integrity. Adv Skin Wound Care 2005;18(3):151-157.

42. International review. Pressure ulcer prevention: pressure, shear, friction and microclimate in context. A consensus document. London: Wounds International, Wounds International Pressure Ulcer Preven- tion, 2010. http://www.woundsinternational.com/media/issues/300/ files/content_8925.pdf. Accessed November 19, 2016.

43. Kokate JY, Leland KJ, Held AM, Hansen GL, Kveen GL, Johnson BA, et al. Temperature-modulated pressure ulcers: a porcine model. Arch Phys Med Rehabil 1995;76(7):666-673.

44. Bronneberg D, Spiekstra SW, Cornelissen LH, Oomens CW, Gibbs S, Baaijens FP, Bouten CV. Cytokine and chemokine release upon prolonged mechanical loading of the epidermis. Exp Dermatol 2007; 16(7):567-573.

45. Alahmari MD, Sapsford RJ, Wedzicha JA, Hurst JR. Dose response of continuous positive airway pressure on nasal symptoms, obstruction and inflammation in vivo and in vitro. Eur Respir J 2012;40(5): 1180-1190.

46. Weng MH. The effect of protective treatment in reducing pressure ulcers for non-invasive ventilation patients. Intensive Crit Care Nurs 2008;24(5):295-299.

This article is approved for Continuing Respiratory Care Education credit. For information and to obtain your CRCE

(free to AARC members) visit

www.rcjournal.com 